\title{
Article \\ Assessing Fast Structure Formation Processes in Isotactic Polypropylene with a Combination of Nanofocus X-ray Diffraction and In Situ Nanocalorimetry
}

\author{
Yaroslav Odarchenko ${ }^{1,2} \oplus$, Martin Rosenthal ${ }^{3, *, t, \neq} \oplus$, Jaime J. Hernandez ${ }^{1, \S}\left(\mathbb{D}\right.$, David Doblas ${ }^{1, \|}$, \\ Emanuela Di Cola ${ }^{3, \mathbb{I}}$, Mikhail Soloviev $2, *$ (i) and Dimitri A. Ivanov $1,4,5, *$ (i)
}

check for

updates

Citation: Odarchenko, Y.; Rosenthal, M.; Hernandez, J.J.; Doblas, D.; Di Cola, E.; Soloviev, M.; Ivanov, D.A. Assessing Fast Structure Formation Processes in Isotactic Polypropylene with a Combination of Nanofocus X-ray Diffraction and In Situ Nanocalorimetry. Nanomaterials 2021, 11, 2652. https://doi.org/10.3390/ nano11102652

Academic Editor: Sergio Brutti

Received: 25 August 2021

Accepted: 4 October 2021

Published: 9 October 2021

Publisher's Note: MDPI stays neutral with regard to jurisdictional claims in published maps and institutional affiliations.

Copyright: (c) 2021 by the authors. Licensee MDPI, Basel, Switzerland. This article is an open access article distributed under the terms and conditions of the Creative Commons Attribution (CC BY) license (https:/ / creativecommons.org/licenses/by/ $4.0 /)$.
1 Institut de Sciences des Matériaux de Mulhouse-IS2M, CNRS UMR 7361, Jean Starcky, 15, F-68057 Mulhouse, France; yaro@finden.co.uk (Y.O.); jaime.hernandez@imdea.org (J.J.H.); david.doblas-jimenez@xfel.eu (D.D.)

2 Department of Biological Sciences, Royal Holloway University of London, Egham, Surrey TW20 0EX, UK

3 European Synchrotron Radiation Facility (ESRF), 38043 Grenoble, France; dicola@sas-analysis.eu

4 Faculty of Chemistry, Lomonosov Moscow State University (MSU), 1 Leninskie Gory, 119991 Moscow, Russia

5 Institute of Problems of Chemical Physics, Russian Academy of Sciences, 142432 Chernogolovka, Russia

* Correspondence: martin.rosenthal@esrf.fr (M.R.); mikhail.soloviev@rhul.ac.uk (M.S.); dimitri.ivanov@uha.fr (D.A.I.)

† Current address: Dutch-Belgian-Beamline DUBBLE@ESRF, 71, Avenue des Martyrs, 38043 Grenoble, France.

$\ddagger$ Current address: Department of Polymer Chemistry and Materials, KU Leuven, Celestijnenlaan 200F, 3001 Leuven, Belgium.

$\S$ Current address: Madrid Institute for Advanced Studies in Nanoscience (IMDEA Nanoscience), C /Faraday 9, Ciudad Universitaria de Cantoblanco, 28049 Madrid, Spain.

|| Current address: European X-ray Free-Electron Laser, 22869 Schenefeld, Germany.

II Current address: SAS-Analysis, 38120 Saint Egreve, France.

Abstract: A combination of in situ nanocalorimetry with simultaneous nanofocus 2D Wide-Angle Xray Scattering (WAXS) was used to study polymorphic behaviour and structure formation in a single micro-drop of isotactic polypropylene (iPP) with defined thermal history. We were able to generate, detect, and characterize a number of different iPP morphologies using our custom-built ultrafast chip-based nanocalorimetry instrument designed for use with the European Synchrotron Radiation Facility (ESRF) high intensity nanofocus X-ray beamline facility. The detected iPP morphologies included monoclinic alpha-phase crystals, mesophase, and mixed morphologies with different mesophase/crystalline compositional ratios. Monoclinic crystals formed from the mesophase became unstable at heating rates above $40 \mathrm{~K} \mathrm{~s}^{-1}$ and showed melting temperatures as low as $\sim 30 \mathrm{~K}$ below those measured for iPP crystals formed by slow cooling. We also studied the real-time melt crystallization of nanogram-sized iPP samples. Our analysis revealed a mesophase nucleation time of around $1 \mathrm{~s}$ and the co-existence of mesophase and growing disordered crystals at high supercooling $\leq 328 \mathrm{~K}$. The further increase of the iPP crystallization temperature to $338 \mathrm{~K}$ changed nucleation from homogeneous to heterogeneous. No mesophase was detected above $348 \mathrm{~K}$. Low supercooling $(\geq 378 \mathrm{~K})$ led to the continuous growth of the alpha-phase crystals. In conclusion, we have, for the first time, measured the mesophase nucleation time of supercooled iPP melted under isothermal crystallization conditions using a dedicated experimental setup designed to allow simultaneous ultrafast chip-based nanocalorimetry and nanofocus X-ray diffraction analyses. We also provided experimental evidence that upon heating, the mesophase converts directly into thermodynamically stable monoclinic alpha-phase crystals via perfection and reorganization and not via partial melting. The complex phase behaviour of iPP and its dependence on both crystallization temperature and time is presented here using a time-temperature-transformation (TTT) diagram.

Keywords: nanocalorimetry; nanofocus X-ray diffraction; isotactic polypropylene; mesophase; crystallization 


\section{Introduction}

Isotactic polypropylene (iPP) combines simple chemical architecture with distinctive polymorphic behaviour and is one of the most intensely studied semicrystalline polymers. When iPP is cooled down slowly from the melt it can often yield several crystalline polymorphs such as $\alpha$-monoclinic, $\beta$-hexagonal, and $\gamma$-triclinic. Quenching iPP melt (cooling rates higher than approximately $100 \mathrm{~K} \mathrm{~s}^{-1}$ ) may also produce a mesophase consisting of conformationally disordered crystals [1,2]. The mesophase stability and its transition to the thermodynamically stable alpha-phase has been widely investigated in the past [3-5]. The results of temperature-resolved X-ray scattering experiments that have been reported previously for slowly heated iPP (rates below $0.1 \mathrm{~K} \mathrm{~s}^{-1}$ ) or iPP annealed at elevated temperatures yielded mesophase transition temperatures of between $350 \mathrm{~K}$ and $360 \mathrm{~K}$ [6,7]. However, some important aspects of the temperature dependence of the reorganization processes in mesophase that happen upon heating are not fully understood. For example, whether the mesophase converts into crystals directly or via partial melting and/or reorganization remains unknown.

Nanocalorimetry allows the study of minute quantities of material at very high heating/cooling rates up to approximately $10^{6} \mathrm{~K} \mathrm{~s}^{-1}$ [8], thus providing an advantage over conventional differential scanning calorimetry (DSC). Traditional commercially available DSC instruments are typically capable of heating/cooling rates of below approximately $10 \mathrm{~K} \mathrm{~s}^{-1}$ and are not suitable for studying fast reorganization processes. Following the earlier developments by L. Allen et al. [9], chip-based calorimetry emerged as a powerful technique for the analysis of different types of materials such as metals $[8,10,11]$, explosives [12], or polymers [13,14]. Mileva et al. used chip-based calorimetry analysis to study the annealing of fully amorphous glassy iPP at $300 \mathrm{~K}$ and reported a mesophase formation time of around $0.1 \mathrm{~s}$ and determined its melting temperature for the first time [3,4]. However, because of the complex phase behaviour and intrinsic polymorphism of iPP, calorimetry studies alone often yield insufficient data. Therefore, additional structural information, such as from wide angle X-ray Scattering (WAXS), Infrared (IR) spectroscopy, or solid-state nuclear magnetic resonance (NMR) analyses, is often required to interpret the results of calorimetry studies.

Combining fast calorimetry with other X-ray diffraction characterization techniques remains a challenge, although some successful experiments employing Fourier transform infrared (FTIR) spectroscopy for studying natural polymers or chromatography for studying propylene copolymers have been reported in the past $[15,16]$. The first successful combination of in situ nanocalorimetry with X-ray diffraction (XRD) was by Vlassak et al. for studying effects of the composition and quenching rate on Au-Cu-Si metallic glasses [17]. Advances in synchrotron optics enabled focusing an X-ray beam to micro- and nanosize, which is beneficial for the study of small samples, which are often required for chipbased nanocalorimetry analysis. A high intensity nanofocused X-ray beamline facility available at the ESRF, which has a sub-200 $\mathrm{nm}$ beam and working distances of up to $4 \mathrm{~mm}$ [18], has allowed us to characterize morphologies formed by several flexible and semi-rigid chain polymers in the past [19-22]. Subsequently a nanocalorimeter was built and integrated in the nanodiffraction setup of the ID13 beamline at ESRF [23,24]. This combination allowed us to not only control and change temperature but also to directly correlate temperature changes with spatially resolved X-ray absorption measurements for the first time. Our in situ nanocalorimetry stage was originally tested by imaging a nanogram size ultra-pure metal particle [23]. We also showed that the dynamic thermal response of the sample measured under quasi-isothermal conditions during X-ray beam exposures provides additional information such as the specific fusion heat for the phase transitions occurring in the sample. We have since conducted simultaneous calorimetric and X-ray scattering analyses of self-assembled carbohydrate-functionalized gold nanoparticles [25], high-energy materials such as CL-20/HMX and CL-20/TNT [26], and a semirigid-chain polymer poly(trimethylene terephthalate) $[27,28]$. As far as we are aware, the only other study where a combination of in situ nanocalorimetry and X-ray diffraction 
has been applied to study polymers was a study determining the isothermal crystallization of polyethylene and polyamide that yielded a fast mesomorphic phase formation time of less than a second for polyamide 11 [29]. Previous research on iPP was largely limited to ex situ measurements of quenched drops of iPP using a commercially available fast scanning chip calorimeter and a microfocus WAXS setup [30]. There, cooling rates of $40 \mathrm{~K} \mathrm{~s}^{-1}$ and $200 \mathrm{~K} \mathrm{~s}^{-1}$ were used, which resulted in the formation of monoclinic crystals or a mesophase, respectively.

The polymorphic behaviour of materials can be conveniently visualised using continuous cooling transformation (CCT), continuous heating transformation (CHT) and time-temperature-transformation (TTT) diagrams [31]. Although, the latter approach is widely utilised in studies of metals, it has rarely been applied to polymers. To the best of our knowledge, only a few CCT studies on iPP and its copolymers have been reported to date [2,32-34]. For example, Cavallo et al. showed that the mesomorphic structure prevails above the critical cooling rate, which decreases with increasing ethylene content from approximately $200 \mathrm{~K} \mathrm{~s}^{-1}$ for a homopolymer to less than $70 \mathrm{~K} \mathrm{~s}^{-1}$ for a copolymer with $7.3 \mathrm{~mol} \%$ of ethylene [2]. Perez and co-workers showed that the rate of mesophase formation can be tuned, covering four orders of magnitude by randomly adding 1-pentene or 1-octene units up to $8.9 \mathrm{~mol} \%$ in iPP $[33,34]$. Choi et al. found that applied spinline stress can enhance alpha-phase formation while preventing mesophase formation under severe quenching conditions (up to $10^{4} \mathrm{~K} \mathrm{~s}^{-1}$ ) [32]. TTT diagrams are useful for understanding the kinetics of phase transitions in isothermally cooled materials. Typically, such data can be generated by performing isothermal crystallization studies from polymer melts. De Santis et al. conducted an isothermal crystallization of iPP, measured the time required to reach the onset of the exothermic peak at a range of different temperatures, and concluded that the solidification mechanism for iPP changes at around $45{ }^{\circ} \mathrm{C}$ [35]. Later, such bimodal crystallization behaviour was confirmed by Silvestre et al. [36] using a combination of calorimetric analysis with the ex situ WAXS of thin $\mathrm{f}$ iPP films that had been rapidly quenched from the melt into water. The authors argued that the crystallization of the iPP mesophase by homogeneous nucleation occurs at temperatures between $\mathrm{Tg}$ and $333 \mathrm{~K}$, whilst higher temperatures promote a heterogeneous nucleation of the monoclinic crystals. However, no data on the polymer phase composition or their dependence on the crystallization time were reported for supercooled iPP melts [36]. In this work, we set out to conduct a comprehensive in situ structural analysis of iPP polymorphism using our chip-based nanocalorimeter instrument combined with nanofocus 2D WAXS. To this end, from their characteristic X-ray diffraction patterns, we have identified and quantified the formation of crystalline, mesomorphic, and amorphous phases in iPP as a function of the isothermal solidification temperature, time, and scanning rates of up to $3000 \mathrm{~K} \mathrm{~s}^{-1}$.

\section{Materials and Methods}

The melt-spun iPP filaments with well-defined diameters and crystallinity with $\mathrm{Mn}=58 \mathrm{~kg} \mathrm{~mol}^{-1}$ and $\mathrm{Mw}=161 \mathrm{~kg} \mathrm{~mol}^{-1}$ were provided by Total Petrochemicals. A detailed characterisation, including the degree of crystallinity of the iPP samples used in this work, has been reported elsewhere [37]. The known thickness of the polymer fibres allowed us to estimate the sample weight from their cylindrical geometry and iPP density of $0.90 \mathrm{~g} / \mathrm{cm}^{-3}$. The WAXS patterns indicate the mesomorphic state of iPP samples (Figure S1). A custom-built ultrafast microelectromechanical systems (MEMS)-based nanocalorimeter instrument (Figure 1a) designed for use with the ESRF high intensity nanofocus X-ray beamline facility was used to generate and study iPP morphologies with a defined thermal history. Small fragments of melt-spun iPP fibres (Figure 1b) typically weighing between $30 \mathrm{ng}$ and $40 \mathrm{ng}$ were positioned within the active area of the calorimetric sensor using a micromanipulator. iPP samples were melted and were then crystallized under defined cooling conditions to produce uniform highly crystalline iPP drops (Figure 1c). The crystallization rates that were used are specified in the temperature-time (TT) profiles. The nanobeam X-ray diffraction measurements were conducted at the ID13 beamline of 
the ESRF (Grenoble, France). X-ray photons with an energy of $14.92 \mathrm{keV}$ were used. The footprint of the beam on a sample of about $150 \times 150 \mathrm{~nm}^{2}$ was achieved using silicon-based compound refractive nano-focusing X-ray lenses with a focal length of $14 \mathrm{~mm}$ [18]. Twodimensional diffraction patterns were collected with a 2D Frelon camera with $50 \times 50 \mu \mathrm{m}$ pixels. Data acquisition was conducted using $2 \times 2$ or $4 \times 4$ binning. The norm of the scattering vector $\mathbf{s :}$

$$
|\mathbf{s}|=2 \sin (\theta) / \lambda
$$

was calibrated using several corundum reflections. The calorimetric measurements were performed with MEMS-type sensors XEN-39392 (Xensor Integration B.V.EJ Delfgauw, The Netherlands) assembled on a ceramic flat plate. The active area of the sensor $\mathrm{Si}_{\mathrm{x}} \mathrm{N}_{\mathrm{y}}$ membrane was $100 \times 100 \mu \mathrm{m}^{2}$.

(a)

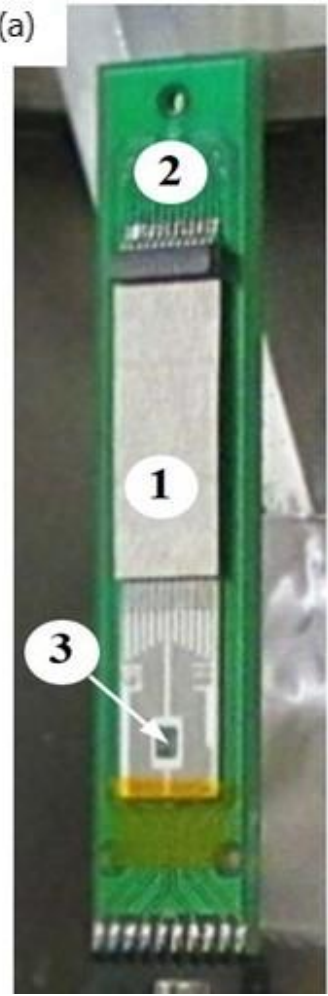

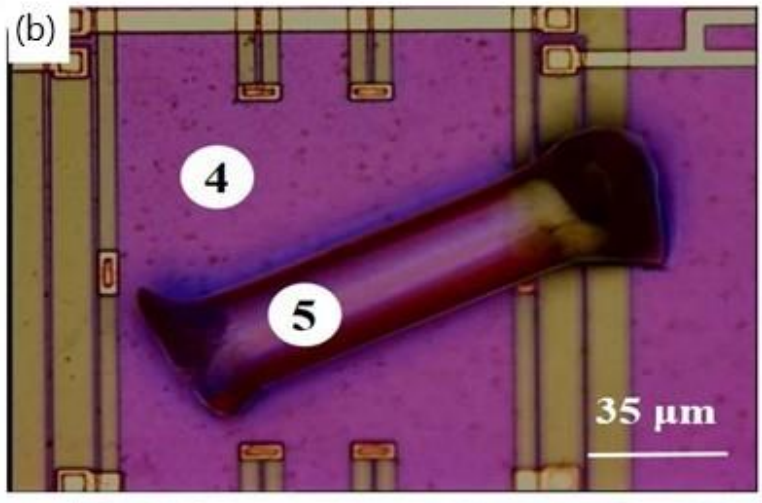

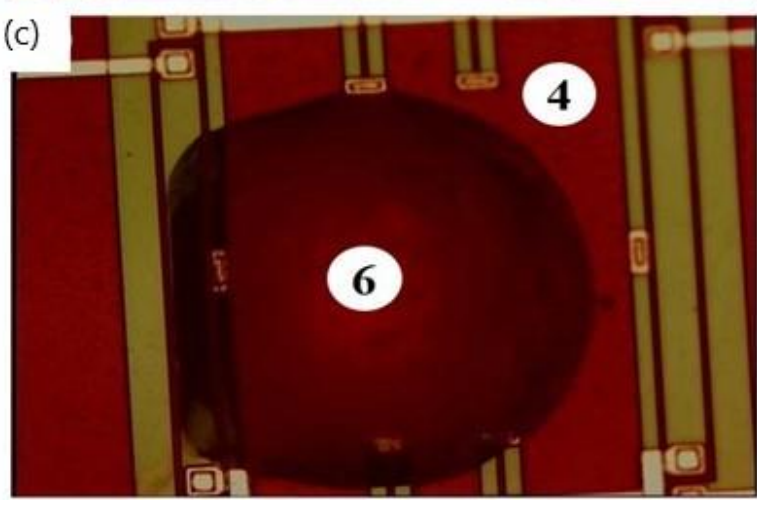

1 - Nanocalorimeter sensor assembly

2 - Custom made X-ray compatible nanocalorimeter sensor holder 3 - X-ray window with the sensor 4 - Active area of the sensor 5 - iPP fiber 6 - iPP molten drop

Figure 1. Nanocalorimeter sensor assembly used for nanofocus 2D Wide-Angle X-ray Scattering (WAXS). (a) Sensor; (b) a fragment of isotactic polypropylene (iPP) fibre deposited on the active area of the sensor; (c) a drop of molten iPP formed after the first heating cycle.

The thickness of the silicon nitride membrane of the integrated sensor was $1 \mu \mathrm{m}$, and it was transparent to the X-ray beam. For 2D WAXS analysis of the isothermal melt crystallization experiments an acquisition time of $1 \mathrm{~s}$ was used. The binning of $4 \times 4$ pixels was selected to achieve a compromise between a high time resolution and the collected number of counts. The detector saving time of $0.4 \mathrm{~s}$ resulted in a WAXS sampling rate of $1.4 \mathrm{~s}$.

\section{Results}

The flat sensor was used in transmission mode at the ID13 nanofocus beamline of ESRF (Figure 1a). The iPP samples (Figure 1b) were melted and were then slowly crystallized at a rate of $0.83 \mathrm{~K} \mathrm{~s}^{-1}$ to produce uniform highly crystalline iPP drops (Figure 1c). The TT profiles used to generate various iPP morphologies, including the highly crystalline (CR) morphologies obtained upon the slow cooling from melt and that were used as a reference, the mesomorphic (M) and the mixed crystalline/mesomorphic (CR_M1, CR_M2) 
morphologies obtained upon the heating of the mesophase, are illustrated in Figure 2a. After preparation, each morphology was analysed using real time calorimetry and nanofocus X-ray diffraction measurements. The 2D WAXS diffractogram corresponding to the CR state is shown in Figure 2b. The reduced 1D WAXS profile of CR exhibits several sharp diffraction peaks that were assigned to the monoclinic phase of iPP (Figure 2c). The nanocalorimetry scan of the CR morphology using a heating rate of $2000 \mathrm{~K} \mathrm{~s}^{-1}$ shows a broad melting peak with a maximum at $427 \mathrm{~K}$ (Peak III in Figure 2d). We estimated the degree of crystallinity to be $47 \%$ from the decomposed WAXS data. The mesomorphic state of iPP (marked "M" in Figure 2a) was generated by quenching the sample in the molten state from $463 \mathrm{~K}$ to $296 \mathrm{~K}$ at $2000 \mathrm{~K} \mathrm{~s}^{-1}$. The corresponding 2D WAXS pattern and integrated 1D curve exhibit two broad scattering peaks characteristic for the iPP mesophase and no further crystallographic reflections indicating the absence of a crystalline register (Figure $2 \mathrm{~b}, \mathrm{c}$ ). The degree of mesomorphicity in the M state was $28 \%$. The nanocalorimetry analysis of the mesomorphic state reveals two endothermic peaks (I and II in Figure 2d), and their nature has been deduced from the WAXS data.

(a)

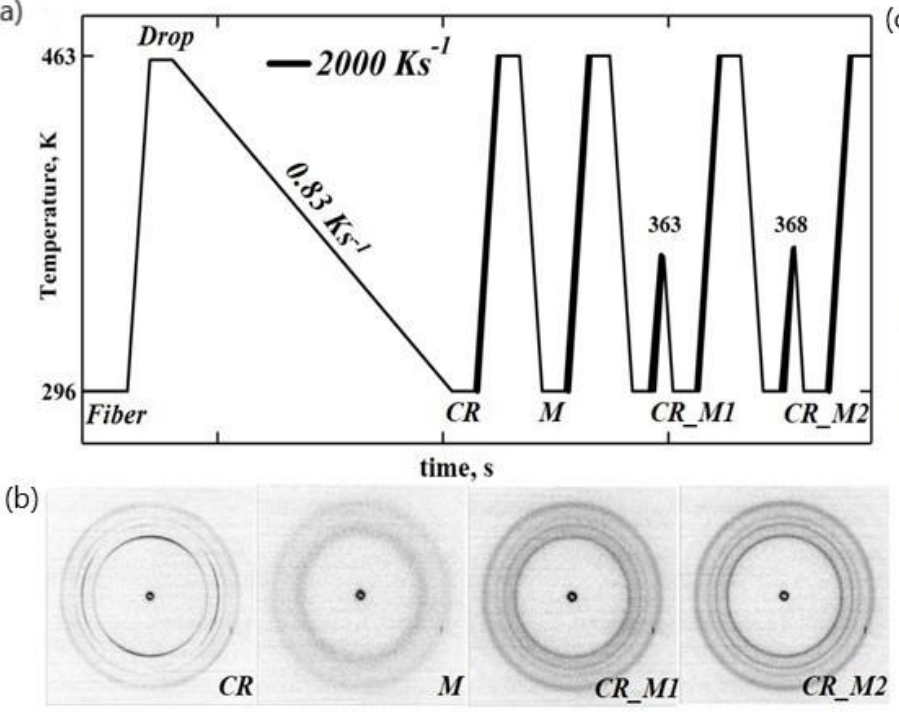

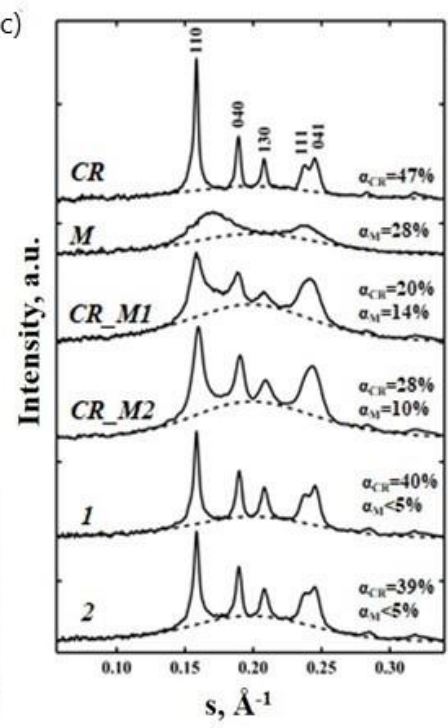

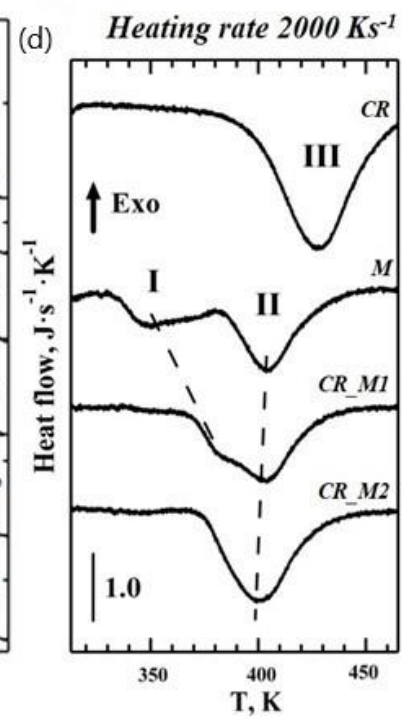

Figure 2. Mesophase-crystal phase transition in iPP. (a) Temperature-time (TT) profiles used to obtain different iPP morphologies; (b) two-dimensional WAXS patterns corresponding to the crystalline $(C R)$, mesomorphic $(M)$, and crystallinemesomorphic (CRM1, CRM2) states; (c) The 1D WAXS profiles of iPP (Y axis—intensity, a.u., $\mathrm{X}$ axis—the modulus of the scattering vector, $\AA^{-1}$ ). The polymer morphologies are indicated above each of the convoluted profiles and include crystalline ( $C R)$, mesomorphic $(M)$, and crystalline-mesomorphic ( $\left.C R \_M 1, C R \_M 2,1,2\right)$ morphologies. Crystalline and mesophase fractions $\left(\alpha_{C R}, \alpha_{M}\right)$ are specified for each of the morphologies. Dashed lines indicate a contribution of the amorphous fraction. Samples 1 and 2, shown here for comparison, were generated by heating the mesophase to $413 \mathrm{~K}$ using heating rates of $0.5 \mathrm{~K} \mathrm{~s}^{-1}$ and $2 \mathrm{~K} \mathrm{~s}^{-1}$ and then quenching the polymer to room temperature. (d) Heating endotherms with a constant rate of $2000 \mathrm{~K} \mathrm{~s}^{-1}$ probing the resulting iPP morphologies. All of the endotherms are normalized by the sample mass and heating rate.

To determine whether the mesophase converts into monoclinic crystals directly or via partial melting (Peak I in Figure 2d) the mesomorphic polymer in state M was annealed at temperatures of $363 \mathrm{~K}$ or $368 \mathrm{~K}$, which are higher than $350 \mathrm{~K}$ (the temperature of the maximum of Peak I), then quenched at the rate of $2000 \mathrm{~K} \mathrm{~s}^{-1}$ and analysed by X-ray (Figure 2). The recorded 2D WAXS patterns of the generated crystalline-mesomorphic states CR_M1 and CR_M2 (annealing temperatures $363 \mathrm{~K}$ and $368 \mathrm{~K}$, respectively) revealed four diffused isotropic peaks (Figure 2c). These morphologies exhibit much broader peaks compared to the CR state in the 1D WAXS profiles (Figure 2c), as estimated from the full width at half maximum (FWHM) values for the 040 peak that increase from 0.0059 for CR to 0.0107 for CR_M2 and 0.0124 for CR_M1, indicating the presence of disordered 
nascent crystals. There is also a noticeable shoulder between the peaks at 110 and 040 of the alpha-phase in CR_M1 and CR_M2, with the s value representing the first reflection of the mesophase (see for example Figure S2). These peaks indicate that the CR_M1 and CR_M2 morphologies comprise three different phases: crystalline, mesomorphic, and amorphous. The relative contents of the crystalline and mesophase fractions depended on the temperature. Increasing the temperature from $363 \mathrm{~K}$ to $368 \mathrm{~K}$ resulted in an increase of the crystalline fraction from $20 \%$ to $28 \%$ and a reduction of mesophase fraction from $14 \%$ to $10 \%$. Therefore, it is reasonable to conclude that the mesophase converts directly into the monoclinic crystal phase via the perfection and reorganisation mechanism, which could be similar to mesophase annealing that has been reported previously [4]. This is supported by the nanocalorimetry data (trace CR_M1 in Figure 2d), where Peak I gradually shifts to a higher temperature. The onset of melting in CR_M1 occurs at lower temperatures compared to the CR state (temperature difference of $30 \mathrm{~K}$ ) indicating differences in the stability of the alpha-phase crystals. The crystalline content in the CR_M1 and CR_M2 states as detected by WAXS analysis is reduced to $20 \%$ and $28 \%$, respectively, compared to $47 \%$ in the CR state (Figure 2c). These results prove the existence of thermodynamically less stable disordered crystals in the CR_M1 and CR_M2 states compared to in the CR form.

To investigate stability of the iPP crystals formed from the mesophase, we subjected our samples to a series of heating cycles with different heating rates. The TT profile that was used is shown in Figure 3a. Diffraction patterns 1-5 (Figure 3b) were generated by heating the mesophase (pattern M) to $413 \mathrm{~K}$, where the heating rates varied from $0.5 \mathrm{~K} \mathrm{~s}^{-1}$ to $2000 \mathrm{~K} \mathrm{~s}^{-1}$, and by then subsequently quenching the polymer to room temperature, marking the initial condition prior to the fast heating experiment.
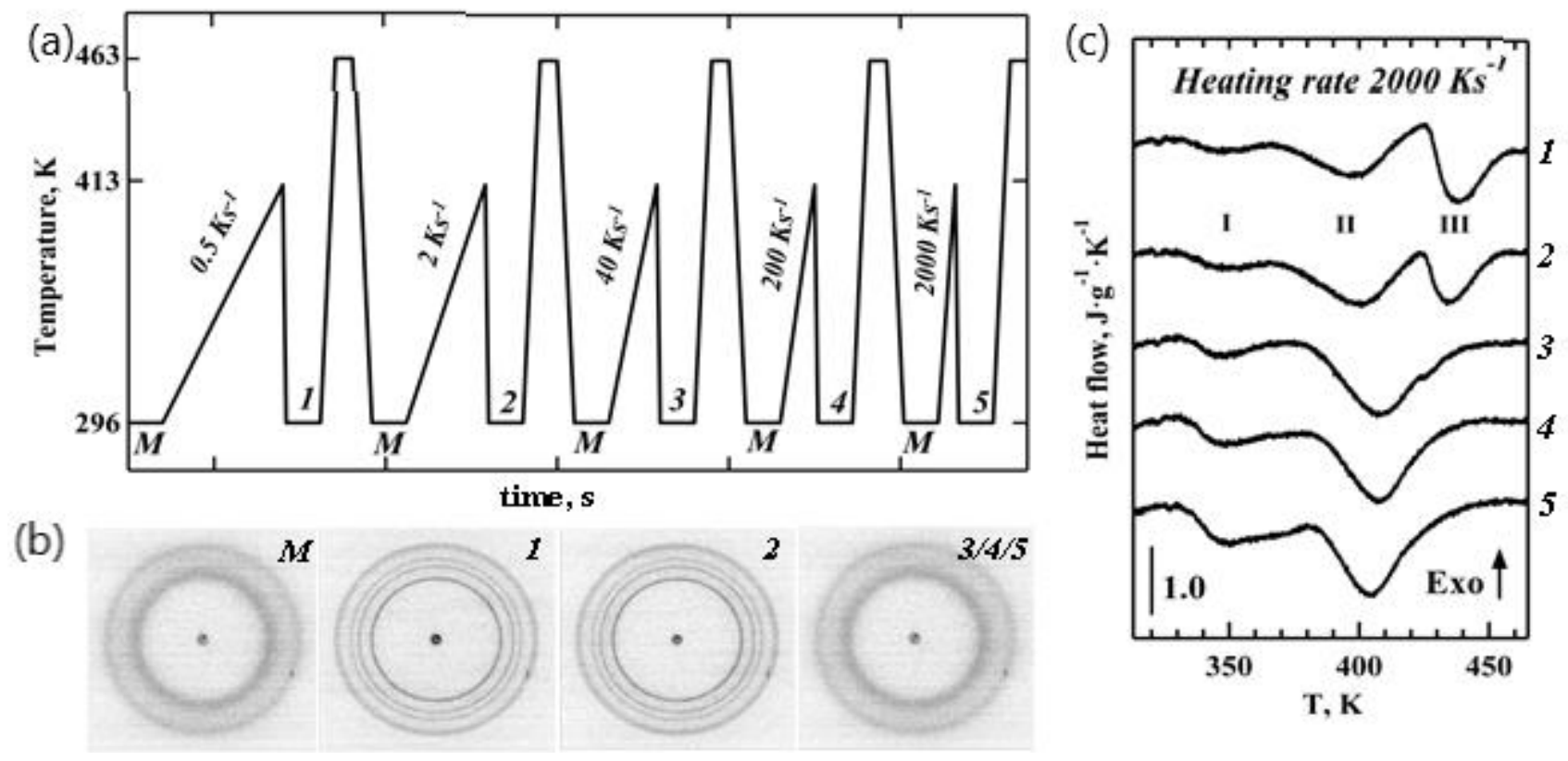

Figure 3. Effect of the heating rate on iPP crystal formation from mesophase. (a) TT profile used for the in situ X-ray structural studies; (b) two-dimensional WAXS patterns M 1-5 of iPP before and after applying different heating rates. (c) Heating endotherm probing states 1-5 at a constant rate of $2000 \mathrm{~K} \mathrm{~s}^{-1}$. All of the endotherms are normalized by the sample mass and the heating rates. For the sake of clarity, images 3, 4, and 5 of mesomorphic iPP are combined.

Several sharp isotropic peaks seen in patterns 1 and 2 (Figure $3 b$ ) correspond to the monoclinic phase of iPP, as seen from the 1D WAXS patterns illustrated in Figure 2c (two bottom profiles). The appearance of crystalline morphologies (points 1 and 2 on the TT profile in Figure 3a) is also evident from the presence of additional high temperature Peak III in the corresponding heating endotherms shown in Figure 3c. Peak I in Figure 3c corresponds to mesophase-crystal transition, as concluded above. Therefore, Peaks II and III represent 
two different populations of alpha-phase iPP crystals obtained upon heating and cooling, respectively, and not the melting of the mesophase. Crystalline morphologies (points 1 and 2 on the TT profile in Figure 3a) show an approximately 7\% lower degree of crystallinity compared to the highly crystalline CR state (Figure 2d). Morphologies (points 3, 4, and 5 on the TT profile in Figure 3a) yielded diffraction patterns that were identical to that of the initial mesomorphic state M. Nanocalorimetry traces 3 to 5 in Figure $3 c$ only have Peaks I and II and are similar to the heating endotherms observed for the mesomorphic state $\mathrm{M}$ of iPP (Figure 2d).

Another TT profile was used to examine the real-time isothermal melt crystallization of iPP (Figure 4a). A nanogram-sized relaxed melt was quenched at a rate of $3000 \mathrm{~K} \mathrm{~s}^{-1}$ to different annealing temperatures. The annealing process was then monitored for $7 \mathrm{~s}$ using nanofocus $\mathrm{X}$-ray diffraction. The temperature profile incorporated multiple crystallization stages (Figure 4a). The first crystallization step was conducted at $308 \mathrm{~K}$, and in each subsequent crystallization step, the temperature was increased by $10 \mathrm{~K}$. The last crystallization step was conducted at $388 \mathrm{~K}$. Selected 2D WAXS patterns and the corresponding 1D-reduced profiles probing iPP morphology are presented in Figure 4. We detected only two diffused peaks at $308 \mathrm{~K}$ and $318 \mathrm{~K}$; these indicate a mesophase formation in the iPP samples (exemplified in Figure $4 \mathrm{~b}$ for $308 \mathrm{~K}$ crystallization cycle). The mesophase fraction in iPP crystallized at $308 \mathrm{~K}$ was $28 \%$ based on the decomposed 1D WAXS profile (from Figure $4 \mathrm{c}$ ), and the same mesophase content was detected at $318 \mathrm{~K}$. The effect of time and temperature on structure formation is summarised in a representative TTT diagram (Figure 5). The increase in the crystallization temperature from $308 \mathrm{~K}$ to $318 \mathrm{~K}$ delayed the mesophase formation by approximately one second (Figure 5).
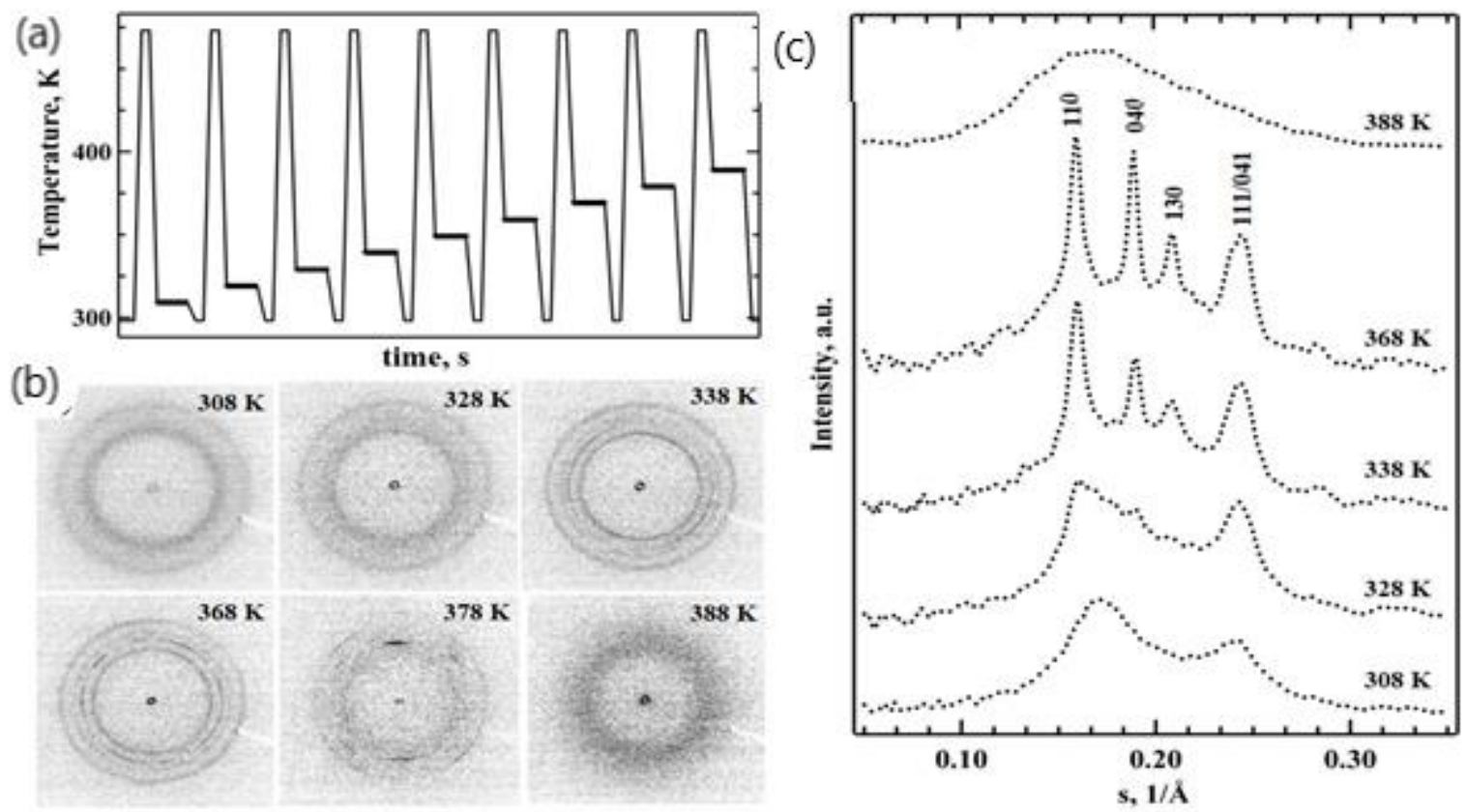

Figure 4. Isothermal melt crystallization of iPP. (a) TT profile used for the real-time X-ray structural studies of the isothermal melt crystallization of iPP with a cooling rate of $3000 \mathrm{~K} \mathrm{~s}^{-1} ;(\mathbf{b})$ selected 2D WAXS patterns probing the structure after $7 \mathrm{~s}$ at different crystallization temperatures from $308 \mathrm{~K}$ to $388 \mathrm{~K}$. (c) Reduced 1D WAXS profiles of the resulting iPP morphology. 


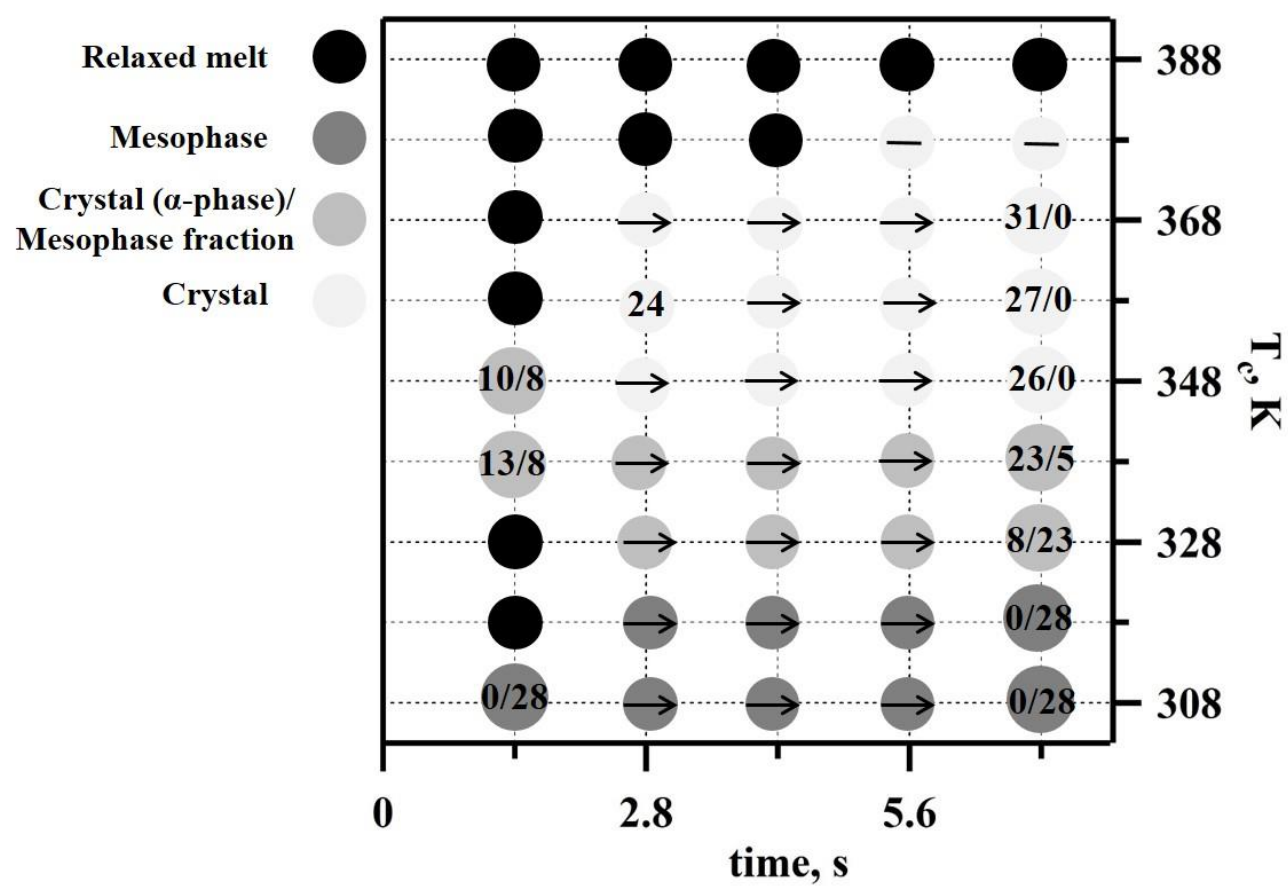

Figure 5. Time-Temperature-Transformation (TTT) diagram for iPP obtained using combined in situ nanocalorimetry and nanfocused X-ray diffraction measurements. Melt, mesophase, and crystalline phases are indicated using different shades of grey. Numbers indicate the calculated crystalline to mesophase fractions. The arrow indicates the same value as the one it is pointing towards.

The time-scale of the polymer isothermal structure formation did not change with the further increase of the crystallization temperature to $328 \mathrm{~K}$. However, the 1D WAXS profiles recorded at $328 \mathrm{~K}$ and above (Figure $4 \mathrm{a}$ ) indicate improved iPP ordering compared to those recorded at $308 \mathrm{~K}$ and $318 \mathrm{~K}$ (Figure $4 \mathrm{c}$ ). A separate reflection around $\mathrm{s}=0.02 \AA^{-1}$ that can be indexed as a 040 peak becomes distinguishable in the iPP crystallized at $328 \mathrm{~K}$ (Figure $4 \mathrm{~b}$ ), indicating the co-existence of highly disordered growing crystals and the mesophase (Figure 4c). Additionally, the first broad peak of the mesophase shifted toward smaller angles and narrowed due to the presence of disordered crystals. Importantly, the mesophase fraction decreased by approximately $5 \%$ in comparison to the samples crystallized at $318 \mathrm{~K}$ (Figure 5). Crystallization conducted at $338 \mathrm{~K}$ yielded prominent crystalline peaks in the 1D WAXS profiles (Figure 4c). Such patterns are typical for alphaphase crystals of isotactic polypropylene, and therefore, the peaks were indexed using unit cells with monoclinic symmetry. The crystalline fraction increased with the crystallization time from 13 to $23 \%$, while the mesophase fraction decreased from 8 to $5 \%$ (Figure 5). A further increase of the crystallization temperature to $348 \mathrm{~K}$ only affected the alpha-phase crystals fraction compared to $338 \mathrm{~K}$ at $1.4 \mathrm{~s}$. The degree of crystallinity of the generated iPP morphology measured after $7 \mathrm{~s}$ reached $26 \%$, whilst no mesophase was present. At 358 and $368 \mathrm{~K}$, the formation of early stage crystals was further delayed by one second, and no mesophase was observed (Figure 5). The degree of crystallinity increased from $24 \%$ to $27 \%$ in the first $2.8 \mathrm{~s}$ at $358 \mathrm{~K}$. At $368 \mathrm{~K}$, a crystallinity value of $31 \%$ was detected at $1.4 \mathrm{~s}$, and it remained stable during the dwelling time. The change in the ratio of the peaks at 040 and 010 indicates further improvement in the molecular packing and therefore the thermodynamic stability of monoclinic crystals (Figure 4c). The appearance of supercooled early stage crystals below $150 \mathrm{~nm}$ in size was delayed by more than $5 \mathrm{~s}$ at $378 \mathrm{~K}$ (Figure 5) and was followed by the appearance of highly oriented crystalline reflections (Figure $4 \mathrm{~b}$ ) that are pertinent to the formation of the spherulitic morphology, similar to those observed for slowly cooled iPP, i.e., the CR in Figure 2b. Finally, crystallization at $388 \mathrm{~K}$ extended the crystal formation time beyond the $7 \mathrm{~s}$ long recording. From the literature, it is well known that the delay in crystallization during heterogeneous crystal formation observed at low 
supercooling is due to the slow crystallization rate and not due to the nuclei formation that is characteristic of a homogeneous nucleation process $[35,36,38]$. The slow crystallization time ( $>7 \mathrm{~s}$ ) observed in this work for $388 \mathrm{~K}$ is in agreement with the recent study of iPP isothermal crystallization performed using fast scanning calorimetry [38], where the reported trend of crystallization time over the range of temperatures that were measured ( $273 \mathrm{~K}$ to $383 \mathrm{~K}$ ) suggested a crystallization time of approximately $5 \mathrm{~s}$ if the temperature was increased to $388 \mathrm{~K}$. As a result, only the isotropic broad diffused halo corresponding to the early stage iPP crystals below $150 \mathrm{~nm}$ in size was recorded (Figure 4c). Different spots on the samples were used to minimise beam-induced damage to the sample within the acquisition time of the experiment.

\section{Discussion}

The nanocalorimeter instrument used in this study can efficiently perform the thermal analysis of a very small quantity of material. The greatly increased sensitivity of the instrument is because much higher heating rates are achievable compared to conventional DSC. The nanocalorimetry sensor consists of a suspended micrometer-thick silicon-rich $\mathrm{Si}_{\mathrm{x}} \mathrm{N}_{\mathrm{y}}$ membrane that contains integrated resistive heating elements and thermocouple hot junctions located within 50-100 $\mu \mathrm{m}$ of the heater strips (Figure 1). The lightweight sensor design provides low thermal inertia that, in combination with the small time constant of the sensor, enables extremely fast heating rates of between $10^{2}$ and $10^{6} \mathrm{~K} \mathrm{~s}^{-1}$. We have previously shown the feasibility of the combined in situ nanocalorimetry with nanofocus X-ray measurements using an indium particle, where we applied both the DC and AC modes [23]. In this work, the DC mode was used to control fast structure formation in isotactic polypropylene. The time resolution of the 2D WAXS detector is this study was contingent upon the acquisition time required to obtain enough counts for a microdrop of polyolefin polymer with considerably smaller X-ray scattering power, unlike, e.g., indium [23].

The use of a nanosized beam provides a unique advantage over conventional WAXS by allowing the study of local crystal organisation with high spatial resolution. Using nanofocus 2D WAXS, we were able, for example, to determine that the poly(propylene adipate) crystals form spirals and not helicoids, giving rise to unique non-radial growth [39]. In this work, the nanofocus WAXS patterns revealed diffraction peaks from oriented crystals (CR in Figure $2 b)$ because the beam size $(150 \mathrm{~nm})$ was comparable with the dimensions of lamellae crystals in a spherulitic superstructure. The formation of alpha-phase crystals following the slow cooling regime of $0.83 \mathrm{~K} \mathrm{~s}^{-1}$ (Figure 2), similar to the regime used in conventional DSC, is in agreement with the results that we reported previously for polymer crystallized in bulk at a rate of $0.05 \mathrm{~K} \mathrm{~s}^{-1}$ [40]. The broad endothermic peak with onset at $397 \mathrm{~K}$ and a maximum peak at $427 \mathrm{~K}$ corresponds to the melting temperature of the alpha-phase crystals and matches the temperature determined previously with help of the DSC [37]. The crystallinity degree of $47 \%$ from WAXS analysis is in good agreement with the value of $41 \%$ obtained from the melting endotherm assuming an enthalpy change of $165 \mathrm{~J} \mathrm{~g}^{-1}$ for a $100 \%$ crystalline sample [41]. The presence of two endothermic peaks observed by nanocalorimetry (marked I and II in Figure 2d) is similar to that reported previously for the mesomorphic iPP prepared from the fully amorphous material at $300 \mathrm{~K}$ for $10 \mathrm{~s}-60 \mathrm{~s}$ and analysed with heating rates ranging between $500 \mathrm{~K} \mathrm{~s}^{-1}$ and $10^{4} \mathrm{~K} \mathrm{~s}^{-1}[3,4]$. Because of the absence of clear exothermic peaks in those studies, Peaks I and II were believed to be related to the mesophases of different compositions [4], and the onset temperature of Peak II, which was higher than $\sim 360 \mathrm{~K}$, was previously attributed to the superheating of the mesomorphic state [4]. Unlike past studies, here, we were able to experimentally confirm the nature of Peak I (mesophase-crystal phase transition) and Peak II (melting of the crystalline phase) from the simultaneous 2D WAXS analyses, and this has verified our interpretation of the heating endotherms generated with nanocalorimetry. Our observation that the mesophase converts directly into the monoclinic crystals in iPP is also in agreement with the recent work by Li et al., where a similar phenomenon was 
observed using a combination of IR and X-ray scattering [42]. The temperature of $413 \mathrm{~K}$ was chosen for the TT profile in Figure 3a and was based on the maximum amount of heat flux from Peak II, corresponding to melting of the iPP crystals formed from the mesophase upon heating (trace M in Figure $2 \mathrm{~d}$ ). The detected value of $\sim 437 \mathrm{~K}$ for Peak III is in good agreement with the melting temperature of the CR state (Figure 2d). Peak III is absent in trace $3-5$ because heating at rates above $40 \mathrm{~K} \mathrm{~s}^{-1}$ do not provide sufficient time for crystals to form and/or to grow. This explains the noticeable decrease of $\sim 30 \mathrm{~K}$ in the melting temperature of the disordered crystals formed from the mesophase in comparison to those measured for the iPP crystals formed by slow cooling (Peak II in Figure S3).

In the past, comparable times of $0.1 \mathrm{~s}$ to $0.3 \mathrm{~s}$ for mesophase formation during the isothermal crystallization of iPP were deduced from the position of the exothermic peaks recorded with fast differential scanning calorimetry [36]. However, at high cooling rates such as $2000 \mathrm{~K} \mathrm{~s}^{-1}$ [36], thermoanalytical curves (the crystallization endotherms) do not allow for differentiation between the mesophase and mixed mesophase-crystalline morphologies $[36,38]$ that could otherwise be detected by X-ray diffraction analysis $[1,43]$. The subsequent technology developments in thermal analysis have furthered our understanding of mesophase formation in semi-crystalline polymers, but to the best of our knowledge, the work of Nishida et al. remains the only study where time-resolved WAXS analysis of the mesophase formation in iPP has been employed [44]. The authors used a temperature jump hot stage compatible with $\mathrm{X}$-rays and optical microscopy and reported a mesophase delay time of $1.6 \mathrm{~s}$ at $293 \mathrm{~K}$ [44]. However, the estimated cooling rates were nonlinear and remained limited to under $100 \mathrm{~K} \mathrm{~s}^{-1}$. Furthermore, the slowing rate of cooling at lower temperatures and the non-isothermal conditions could have affected the measurements of the mesophase formation kinetics [44].

In this work, we consistently detected a delay in the mesophase formation of approximately one second under isothermal conditions at a range of supercooling temperatures (Figure 5). We were also able to identify and quantify the mesophase and alpha-phase crystal fractions present in the mixed mesophase-crystalline morphologies (Figure 5). In the past, a similar time scale for mesophase development in iPP was observed in non-isothermal crystallization experiments using a WAXS of polymer film wrapped in aluminium foil [1]. The co-existence of highly disordered supercooled crystals and the mesophase in iPP crystallized at $328 \mathrm{~K}$ discovered in this work from WAXS analyses corroborate data on the bimodal crystallization kinetics around $328 \mathrm{~K}$ that were obtained using calorimetry alone [35,36]. The nanofocus beam also allowed us to obtain the first independent proof of change in crystal nucleation kinetics from homogeneous to heterogeneous at temperatures above $338 \mathrm{~K}$. Our results support previous studies of supercooled iPP melts, where a similar conclusion was made based solely on the calorimetry data for the temperature of $333 \mathrm{~K}$ since polymer composition was only probed using ex situ WAXS [36].

\section{Conclusions}

In conclusion, we reported a successful experiment that was conducted using our dedicated custom-built ultrafast chip-based nanocalorimetry instrument designed for use with the ESRF high intensity nanofocus X-ray beamline. Our experimental approach revealed novel insights into fast structure formation processes in an industrially important semicrystalline polymer. In this work, we reported on the nucleation time and transformation kinetics of the mesophase in iPP and documented its direct transition through perfection and reorganisation into monoclinic crystals upon heating or isothermally and quantified the mesophase to alpha-phase crystal fraction in mixed mesophase-crystalline morphologies of iPP. We showed that disordered iPP crystals formed from the mesophase become unstable at heating rates above $40 \mathrm{~K} \mathrm{~s}^{-1}$ and exhibit melting temperatures $\sim 30 \mathrm{~K}$ lower than those measured for crystals formed by slow cooling. The time-temperaturetransformation diagram was generated for a wide range of temperatures, from $308 \mathrm{~K}$ to $388 \mathrm{~K}$, by performing isothermal melt-solidification of polymer microdrops. The TTT chart revealed the complex phase behaviour of iPP as a function of the crystallization 
temperature and time. For the first time, we have characterised mesophase nucleation time under isothermal conditions and quantified the mesophase to alpha-phase crystal fraction in mixed mesophase-crystalline morphologies of iPP using a dedicated experimental setup designed to allow simultaneous ultrafast chip-based nanocalorimetry and nanofocus X-ray diffraction analyses. The advantage of using nanofocus 2D WAXS over conventional WAXS has been demonstrated by detecting the change from homogeneous to heterogeneous crystal nucleation regimes. Our study of real-time isothermal melt crystallization of iPP reported here provides novel insights that may be useful for the engineering and processing of this industrially important polymer.

Supplementary Materials: The following are available online at https://www.mdpi.com/article/10 .3390/nano11102652/s1, Figure S1: Two-dimensional WAXS image of the iPP fibre material used; Figure S2: Decomposed 1D WAXS curve for CR_M1 morphology; Figure S3: Heating endotherms of iPP mesophase formation at rates between 40 and $2000 \mathrm{~K} \mathrm{~s}^{-1}$.

Author Contributions: Conceptualization, D.A.I.; methodology, M.R. and D.A.I.; software, M.R.; formal analysis, Y.O.; investigation, Y.O., D.D. and J.J.H.; resources, E.D.C.; writing-original draft preparation, Y.O.; writing-review and editing, M.S.; supervision, M.S. and D.A.I.; funding acquisition, D.A.I. and M.S. All authors have read and agreed to the published version of the manuscript.

Funding: This research was funded by BBSRC funding grant number BB/L018152/1 to Y.O. and M.S.; Russian Foundation for Basic Research project no. 19-29-12049 funding to D.A.I.; State Task No AA19-119101590029-0 funding support to D.A.I.

Data Availability Statement: The data presented in this study are available on request from the corresponding authors.

Conflicts of Interest: The authors declare no conflict of interest.

\section{References}

1. Cavallo, D.; Portale, G.; Balzano, L.; Azzurri, F.; Bras, W.; Peters, G.W.; Alfonso, G.C. Real-time WAXD detection of mesophase development during quenching of propene/ethylene copolymers. Macromolecules 2010, 43, 10208-10212. [CrossRef]

2. Cavallo, D.; Azzurri, F.; Floris, R.; Alfonso, G.C.; Balzano, L.; Peters, G.W. Continuous cooling curves diagrams of propene/ethylene random copolymers. The role of ethylene counits in mesophase development. Macromolecules 2010, 43, 2890-2896. [CrossRef]

3. Mileva, D.; Androsch, R.; Zhuravlev, E.; Schick, C. Temperature of Melting of the Mesophase of Isotactic Polypropylene. Macromolecules 2009, 42, 7275-7278. [CrossRef]

4. Mileva, D.; Androsch, R.; Zhuravlev, E.; Schick, C.; Wunderlich, B. Isotropization, perfection and reorganization of the mesophase of isotactic polypropylene. Thermochim. Acta 2011, 522, 100-109. [CrossRef]

5. Caldas, V.; Brown, G.R.; Nohr, R.S.; MacDonald, J.G.; Raboin, L.E. The structure of the mesomorphic phase of quenched isotactic polypropylene. Polymer 1994, 35, 899-907. [CrossRef]

6. Wang, Z.-G.; Hsiao, B.S.; Srinivas, S.; Brown, G.M.; Tsou, A.H.; Cheng, S.Z.; Stein, R.S. Phase transformation in quenched mesomorphic isotactic polypropylene. Polymer 2001, 42, 7561-7566. [CrossRef]

7. Konishi, T.; Nishida, K.; Kanaya, T. Crystallization of Isotactic Polypropylene from Prequenched Mesomorphic Phase. Macromolecules 2006, 8035-8040. [CrossRef]

8. Yang, B.; Peng, Q.; Milkereit, B.; Springer, A.; Liu, D.; Rettenmayr, M.; Schick, C.; Keßler, O. Nucleation behaviour and microstructure of single Al-Si12 powder particles rapidly solidified in a fast scanning calorimeter. J. Mater. Sci. 2021, 56, 12881-12897. [CrossRef]

9. Allen, L.H.; Ramanath, G.; Lai, S.L.; Ma, Z.; Lee, S.; Allman, D.D.J.; Fuchs, K.P. 1,000,000 C/s thin film electrical heater: In situ resistivity measurements of $\mathrm{Al}$ and $\mathrm{Ti} / \mathrm{Si}$ thin films during ultra rapid thermal annealing. Appl. Phys. Lett. 1994, 64, 417-419. [CrossRef]

10. Lai, S.; Guo, J.; Petrova, V.; Ramanath, G.; Allen, L. Size-Dependent Melting Properties of Small Tin Particles: Nanocalorimetric Measurements. Phys. Rev. Lett. 1996, 77, 99-102. [CrossRef] [PubMed]

11. Lopeandía, A.F.; Rodríguez-Viejo, J. Size-dependent melting and supercooling of Ge nanoparticles embedded in a SiO $\mathrm{O}_{2}$ thin film. Thermochim. Acta 2007, 461, 82-87. [CrossRef]

12. Piazzon, N.; Rosenthal, M.; Bondar, A.; Spitzer, D.; Ivanov, D.A. Characterization of explosives traces by the nanocalorimetry. J. Phys. Chem. Solids 2010, 71, 114-118. [CrossRef]

13. Minakov, A.A.; Mordvintsev, D.A.; Schick, C. Isothermal reorganization of poly(ethylene terephthalate) revealed by fast calorimetry $\left(1000 \mathrm{~K} \mathrm{~s}^{-1} ; 5 \mathrm{~ms}\right)$. Faraday Discuss. 2005, 128, 261-270. [CrossRef] [PubMed] 
14. Odarchenko, Y.I.; Anokhin, D.V.; Doblas, D.; Rosenthal, M.; Hernandez, J.J.; Vidal, L.; Sijbrandi, N.J.; Kimenai, A.J.; Mes, E.P.C.; Broos, R.; et al. Primary Chemical Sequence Ultimately Determines Crystal Thickness in Segmented All-Aliphatic Copolymers. Macromolecules 2014, 47, 22, 7890-7899. [CrossRef]

15. Cebe, P.; Hu, X.; Kaplan, D.L.; Zhuravlev, E.; Wurm, A.; Arbeiter, D.; Schick, C. Beating the heat-Fast scanning melts silk beta sheet crystals. Sci. Rep. 2013, 3, 1130. [CrossRef]

16. Cheruthazhekatt, S.; Pijpers, T.F.J.; Harding, G.W.; Mathot, V.B.F.; Pasch, H. Compositional Analysis of an Impact Polypropylene Copolymer by Fast Scanning DSC and FTIR of TREF-SEC Cross-Fractions. Macromolecules 2012, 45, 5866-5880. [CrossRef]

17. Gregoire, J.M.; McCluskey, P.J.; Dale, D.; Ding, S.; Schroers, J.; Vlassak, J.J. Combining combinatorial nanocalorimetry and X-ray diffraction techniques to study the effects of composition and quench rate on Au-Cu-Si metallic glasses. Scr. Mater. 2012, 66, 178-181. [CrossRef]

18. Boye, P.; Feldkamp, J.M.; Patommel, J.; Schwab, A.; Stephan, S.; Hoppe, R.; Schroer, C.G.; Burghammer, M.; Riekel, C.; Van Der Hart, A.; et al. Nanofocusing refractive X-ray lenses: Fabrication and modeling. J. Phys. Conf. Ser. 2009, 186, 012063. [CrossRef]

19. Rosenthal, M.; Bar, G.; Burghammer, M.; Ivanov, D.A. On the Nature of Chirality Imparted to Achiral Polymers by the Crystallization Process. Angew. Chem. Int. Ed. 2011, 123, 9043-9047. [CrossRef]

20. Rosenthal, M.; Portale, G.; Burghammer, M.; Bar, G.; Samulski, E.T.; Ivanov, D.A. Exploring the Origin of Crystalline Lamella Twist in Semi-Rigid Chain Polymers: The Model of Keith and Padden revisited. Macromolecules 2012, 45, 7454-7460. [CrossRef]

21. Rosenthal, M.; Burghammer, M.; Bar, G.; Samulski, E.T.; Ivanov, D.A. Switching Chirality of Hybrid Left-Right Crystalline Helicoids Built of Achiral Polymer Chains: When Right to Left Becomes Left to Right. Macromolecules 2014, 47, 8295-8304. [CrossRef]

22. Ivanov, D.A.; Rosenthal, M. Microstructure of Banded Polymer Spherulites: New Insights from Synchrotron Nanofocus X-ray Scattering. In Polymer Crystallization II; Auriemma, F., Alfonso, G.C., de Rosa, C., Eds.; Springer International Publishing: Cham, Switzerland, 2017; pp. 95-126.

23. Rosenthal, M.; Doblas, D.; Hernandez, J.J.; Odarchenko, Y.I.; Burghammer, M.; Di Cola, E.; Spitzer, D.; Antipov, A.E.; Aldoshin, L.S.; Ivanov, D.A. High-resolution thermal imaging with a combination of nano-focus X-ray diffraction and ultra-fast chip calorimetry. J. Synchrotron Radiat. 2014, 21, 223-228. [CrossRef]

24. Rosenthal, M.; Melnikov, A.P.; Rychkov, A.A.; Doblas, D.; Anokhin, D.V.; Burghammer, M.; Ivanov, D.A. Design of an in situ setup combining nanocalorimetry and nano- or micro-focus X-ray scattering to address fast structure formation processes. In Fast Scanning Calorimetry; Schick, C., Mathot, V., Eds.; Springer International Publishing: Cham, Switzerland, 2016 ; pp. $299-326$.

25. Riekel, C.; Di Cola, E.; Burghammer, M.; Reynolds, M.; Rosenthal, M.; Doblas, D.; Ivanov, D.A. Thermal Transformations of Self-Assembled Gold Glyconanoparticles Probed by Combined Nanocalorimetry and X-ray Nanobeam Scattering. Langmuir 2015, 31, 529-534. [CrossRef]

26. Doblas, D.; Rosenthal, M.; Burghammer, M.; Chernyshov, D.; Spitzer, D.; Ivanov, D.A. Smart Energetic Nanosized Co-Crystals: Exploring Fast Structure Formation and Decomposition. J. Cryst. Growth Des. 2016, 16, 432-439. [CrossRef]

27. Melnikov, A.P.; Rosenthal, M.; Rodygin, A.I.; Doblas, D.; Anokhin, D.V.; Burghammer, M.; Ivanov, D.A. Re-exploring the double-melting behavior of semirigid-chain polymers with an in situ combination of synchrotron nano-focus X-ray scattering and nanocalorimetry. Eur. Polym. J. 2016, 81, 598-606. [CrossRef]

28. Melnikov, A.P.; Rosenthal, M.; Ivanov, D.A. What Thermal Analysis Can Tell Us About Melting of Semicrystalline Polymers: Exploring the General Validity of the Technique. ACS Macro Lett. 2018, 7, 1426-1431. [CrossRef]

29. Baeten, D.; Mathot, V.B.F.; Pijpers, T.F.J.; Verkinderen, O.; Portale, G.; Van Puyvelde, P.; Goderis, B. Simultaneous Synchrotron WAXD and Fast Scanning (Chip) Calorimetry: On the (Isothermal) Crystallization of HDPE and PA11 at High Supercoolings and Cooling Rates up to 200 degrees C s-1. Macromol. Rapid Commun. 2015, 36, 1184-1191. [CrossRef]

30. Van Drongelen, M.; Meijer-Vissers, T.; Cavallo, D.; Portale, G.; Poel, G.V.; Androsch, R. Microfocus wide-angle X-ray scattering of polymers crystallized in a fast scanning chip calorimeter. Thermochim. Acta 2013, 563, 33-37. [CrossRef]

31. Moniz, B.J. Metallurgy; American Technical Publishers Inc.: Orland Park, IL, USA, 2007.

32. Choi, C.; White, J.L. Correlation and modeling of the occurrence of different crystalline forms of isotactic polypropylene as a function of cooling rate and uniaxial stress in thin and thick parts. Polym. Eng. Sci. 2000, 40, 645-655. [CrossRef]

33. Pérez, E.; Gómez-Elvira, J.M.; Benavente, R.; Cerrada, M.L. Tailoring the Formation Rate of the Mesophase in Random Propyleneco-1-pentene Copolymers. Macromolecules 2012, 45, 6481-6490. [CrossRef]

34. Arranz-Andrés, J.; Parrilla, R.; Cerrada, M.L.; Pérez, E. Mesophase Formation in Random Propylene-co-1-octene Copolymers. Macromolecules 2013, 46, 8557-8568. [CrossRef]

35. De Santis, F.; Adamovsky, S.; Titomanlio, G.; Schick, C. Isothermal Nanocalorimetry of Isotactic Polypropylene. Macromolecules 2007, 40, 9026-9031. [CrossRef]

36. Silvestre, C.; Cimmino, S.; Duraccio, D.; Schick, C. Isothermal crystallization of isotactic poly(propylene) studied by superfast calorimetry. Macromol. Rapid Commun. 2007, 28, 875-881. [CrossRef]

37. Colombe, G.; Gree, S.; Lhost, O.; Dupire, M.; Rosenthal, M.; Ivanov, D.A. Correlation between mechanical properties and orientation of the crystalline and mesomorphic phases in isotactic polypropylene fibers. Polymer 2011, 52, 5630-5643. [CrossRef]

38. Mileva, D.; Wang, J.; Gahleitner, M.; Jariyavidyanont, K.; Androsch, R. New Insights into Crystallization of Heterophasic Isotactic Polypropylene by Fast Scanning Chip Calorimetry. Polymers 2020, 12, 1683. [CrossRef] 
39. Rosenthal, M.; Hernandez, J.J.; Odarchenko, Y.I.; Soccio, M.; Lotti, N.; Di Cola, E.; Burghammer, M.; Ivanov, D.A. Non-radial growth of helical homopolymer crystals: Breaking the paradigm of the polymer spherulite microstructure. Macromol. Rapid Commun. 2013, 34, 1815-1819. [CrossRef] [PubMed]

40. Selikhova, V.I.; Bessonova, N.P.; Konyukhova, E.V.; Odarchenko, Y.I.; Sinevich, E.A.; Chvalun, S.N.; Rieger, B. Effect of stereoregularity on the structure and thermophysical characteristics of isotactic polypropylene. Polym. Sci. Ser. A 2008, 50, $1071-1081$. [CrossRef]

41. Wunderlich, B. Macromolecular Physics; Academic Press: New York, NY, USA, 1980; pp. 61-64.

42. Li, X.; Ding, J.; Liu, Y.; Tian, V. A new model for mesomorphic-monoclinic phase transition of isotactic polypropylene. Polymer 2017, 108, 242-250. [CrossRef]

43. Zia, Q.; Andros, R.; Radusch, H.-J.; Piccarolo, S. Morphology, reorganization and stability of mesomorphic nanocrystals in isotactic polypropylene. Polymer 2006, 47, 8163-8172. [CrossRef]

44. Nishida, K.; Okada, K.; Asakawa, H.; Matsuba, G.; Ito, K.; Kanaya, T.; Kaji, K. In situ observations of the mesophase formation of isotactic polypropylene-A fast time-resolved X-ray diffraction study. Polym. J. 2012, 44, 95-101. [CrossRef] 